Chemical Engineering Research Bulletin 17(2015) 18-24

\title{
EXPERIMENENTAL STUDY OF THE EFFECT OF ORIFICE INCLINATION ON GAS HOLDUP IN BUBBLE COLUMNS
}

\author{
Iqbal Hossain ", Abdul Rakib", Badruddhuza Talukder and Hamidul Hira \\ Department of Chemical Engineering, Bangladesh University of Engineering \&Technology, Dhaka-1000, \\ Bangladesh
}

Received 1 November 2014; received in revised form 10 March 2015

\begin{abstract}
Gas holdup in the column section of bubble columns is determined by a large number of operating-design variables-parameters. In this study the effect of orifice inclination on the gas holdup is investigated at various superficial gas velocities. It is observed that the effect depends largely on the gas velocities. At very low gas velocities such as $0.015-0.076 \mathrm{~cm} / \mathrm{s}$ where truly dispersed-bubble regime prevails, an inclination of the orifice keeping the size unchanged tends to decrease the gas holdup. However this effect diminishes with increasing gas velocity and no remarkable effect is found at relatively higher gas velocities like $2.20-8.50 \mathrm{~cm} / \mathrm{s}$ where dispersed-transition-coalesced bubble regimes prevail. Therefore when bubble columns are intended to operate at very low superficial gas velocities, the orifice inclination is also an alternative option to control the gas holdup at the desired level. The experimental results produced in this study would be useful for the development and validation of proper mathematical model.
\end{abstract}

Keywords: Bubble Columns; Gas Holdup; Gas Distributor; Orifice; Orifice Inclination.

Available online at http://www.Ganglajol.info/index.php/CERB

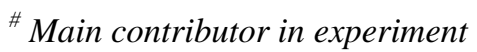

* To whom all correspondence should be addressed.

(email: iqbalhossain@che.buet.ac.bd)
} 


\section{Chemical Engineering Research Bulletín 17(2015) 18-24}

\section{INTRODUCTION}

Many chemical, biochemical and petrochemical industrial processes involve the use of bubble columns $[1,2]$. Knowledge on the bubble properties such as bubble size distribution and gas holdup is vital to the modeling, design and scale-up of those columns [3]. The gas holdup governs the mass transfer through interfacial area and liquid phase turbulence, and the mass transfer is the controlling step of numerous chemical and biochemical processes [4-6]. The behavior of the gas holdup has been attributed to many factors, including the physical properties of gas/liquid phase, column geometry, the operating variables such as pressure, gas velocity, temperature and solid loading, and gas distributor design, etc. Though numerous studies on the effect of those parameters on gas holdup are available in literature [7-13], the effect of gas distributor design variable on gas holdup is not fully known yet.

Among gas distributors of various types, the perforated flat plate gas distributor is mostly used in bubble columns. The design of this distributor considers mainly the diameter, thickness, number, pitch and arrangement of the orifices as variables $[14,15]$. The effect of those variables on the gas holdup is more or less known [16,17]. However, in spite of having the tuning possibility, the orifice inclination in a perforated flat plate gas distributor is not considered or practiced as a design variable yet. This is probably due to the lack of knowledge on the effect of orifice inclination on the gas holdup. Therefore the objective of this study is to investigate and analyze the effect of orifice inclination on the gas holdup considering both single and multiple-orifice flat plate gas distributors and present quantitative experimental data that can be used for the development and validation of proper mathematical model.

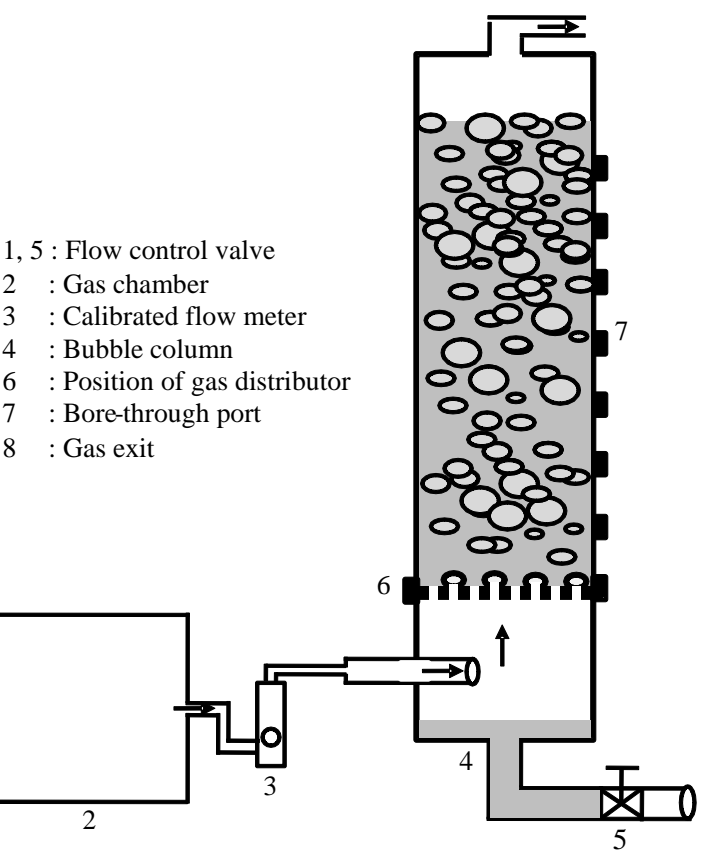

Figure 1: Schematic of the Experimental Setup Used in the Study

\section{EXPERIMENTAL}

The experimental setup used is shown in Figure 1. The acrylic made column has an internal diameter of $14 \mathrm{~cm}$. The empty plenum below the gas distributor has an average volume of $2000 \mathrm{~cm}^{3}$. The acrylic made gas distributor has a thickness of 0.50 $\mathrm{cm}$ and orifice(s) of $0.50 \mathrm{~cm}$ average diameter. The experiment is carried out both in single and multiple orifice distributors; in multiple-orifice distributor, the orifices are in a triangular configuration with a pitch of $2.00 \mathrm{~cm}$. Compressed air is used as the gas source. The air flow rate is controlled by a calibrated volumetric flow-meter. Water is used as the liquid phase and the static liquid height is maintained $40 \mathrm{~cm}$ at the beginning of each run. Three transparent rulers are vertically attached in the column wall at 


\section{Chemical Engineering Research Bulletin 17(2015) 18-24}

three different positions maintaining $120^{\circ}$ angle each other to determine the average bed height in the column under dynamic condition. The superficial gas velocities considered are within the range of 2.20-8.50 $\mathrm{cm} / \mathrm{s}$ and $0.015-0.076 \mathrm{~cm} / \mathrm{s}$. Three inclinations of $0^{\circ}, 15^{\circ}$ and $30^{\circ}$ as shown in Figure 2 are considered to investigate the effect of orifice inclination on gas holdup. It is important to note that each orifice inclination considered has the opening of same size i.e., $0.50 \mathrm{~cm}$. The gas holdup at an experimental condition is calculated by: $\varepsilon_{\mathrm{G}}=$ $1-\mathrm{h}_{\mathrm{o}} / \mathrm{h}_{\mathrm{G}}$; where $\mathrm{h}_{\mathrm{o}}$ and $\mathrm{h}_{\mathrm{G}}$ are the static or initial liquid height and the liquid height in the column under gas flowing condition, respectively [18].

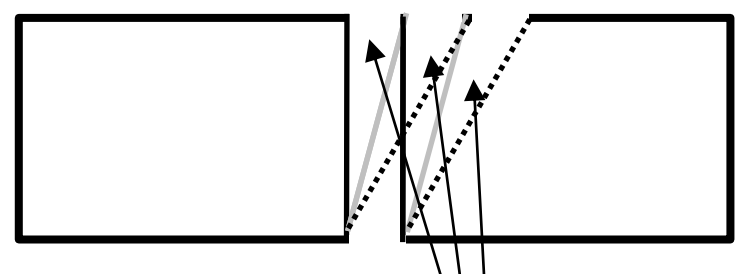

Black solid: $0^{\circ}$ Inclined orifice

Gray solid : $15^{\circ}$ Inclined prifice

Black dotted : $30^{\circ}$ Inclined orifice

Figure 2: Different Orifice Inclinations Considered in the study

\section{RESULTS AND DISCUSSION}

Bubble columns with relatively larger diameters have two distinct regimes of operation namely "dispersed-bubble regime" where bubbles show nearly uniform properties and "coalesced-bubble regime" where a severe irregularity in bubble properties is observed [1, 19-21]. The superficial gas velocity at which flow regime transition occurs depends on a number of factors such as liquid and gas properties, column diameter, column heightto-diameter ratio, and distributor design, etc. However air-water systems are reported to have an experimental regime transition superficial gas velocity in the range of 2.4 $\mathrm{cm} / \mathrm{s}$ to $6.5 \mathrm{~cm} / \mathrm{s}$ at ambient pressure [2225]. Therefore $2.20,4.57,6.40$, and 8.50 $\mathrm{cm} / \mathrm{s}$ gas velocities are primarily chosen to evaluate the effect of orifice inclination ( 0 $30^{\circ}$ ) on the gas holdup using multiple orifice distributor gas plate. Figure 3 shows that orifice inclination $\left(0-30^{\circ}\right)$ has no remarkable effect on the gas holdup at the gas velocities considered here. The visualization of bubbling behaviors from the column outside during experiment showed that column operates almost in the transition or coalesced-bubble regime at the gas velocities of $4.57,6.40$ and $8.50 \mathrm{~cm} / \mathrm{s}$. However the visualization indicated that column operates in the homogeneous regime at the gas velocity of $2.20 \mathrm{~cm} / \mathrm{s}$. Hence it is concluded that orifice inclination does not have any remarkable effect on the gas holdup both in the dispersed- and coalescedbubble regimes at the gas velocities (2.20$8.50 \mathrm{~cm} / \mathrm{s}$ ) considered.

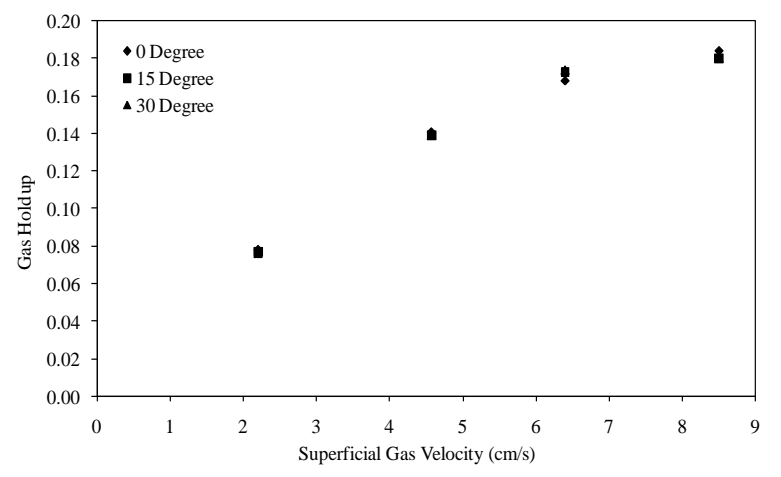

Figure 3: Investigation of the Effect of Orifice Inclination on Gas Holdup at the Gas Velocities of 2.20-8.50 cm/s in a Multiple Orifice Gas Distributor Plate

Subsequently, the effect of orifice inclination on the gas holdup is investigated at very low gas velocities of 0.015-0.076 $\mathrm{cm} / \mathrm{s}$ employing the same multiple orifice gas distributor. Figure 4 reveals the existence of an obvious effect of orifice inclination on the gas holdup. The gas 
holdup decreases with the increase of orifice inclination in the entire gas velocity range of $0.015-0.076 \mathrm{~cm} / \mathrm{s}$. The investigation is further extended to single orifice gas distributor for the same superficial gas velocities. It is found as shown in Figure 5 that gas holdup decreases with increasing inclination for single orifice gas distributor too.

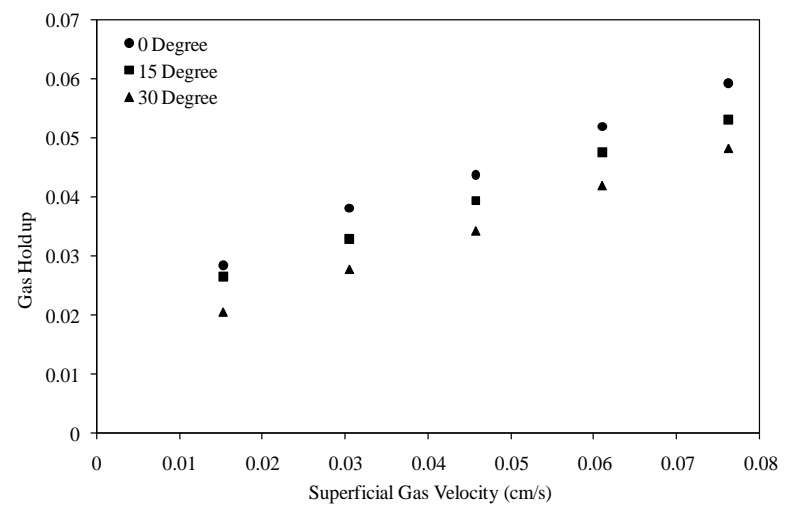

Figure 4: Investigation of the Effect of Orifice Inclination on Gas Holdup at the Gas Velocities of $0.015-0.076 \mathrm{~cm} / \mathrm{s}$ in a Multiple Orifice Gas Distributor Plate

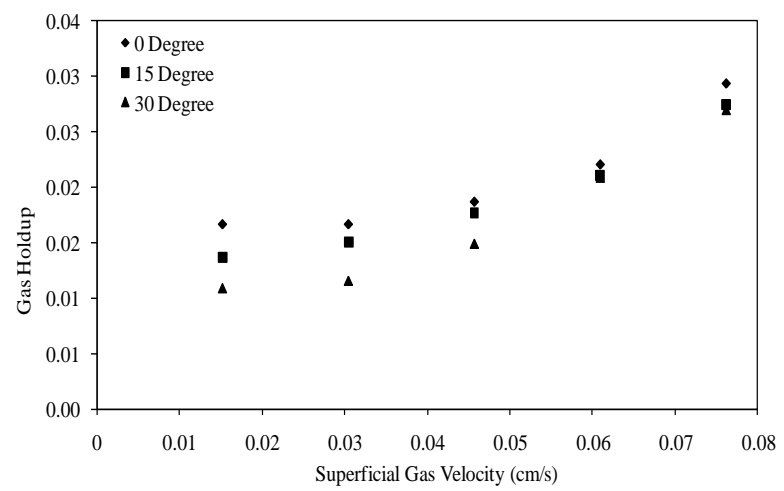

Figure 5: Investigation of the Effect of Orifice Inclination on Gas Holdup at the Gas Velocities of $0.015-0.076 \mathrm{~cm} / \mathrm{s}$ in a Single Orifice Gas Distributor Plate

A possible explanation or hypothesis on the basis of "bubble formation phenomenon at orifice" can be offered to rationalize the observed effect. It is known that the bubble formation at orifice can be divided into initiation, expansion and detachment stages [26]. After the initiation at the tip of orifice a bubble expands until it detaches from the orifice periphery as shown in Figure 6 by the forces acting in the upward direction.

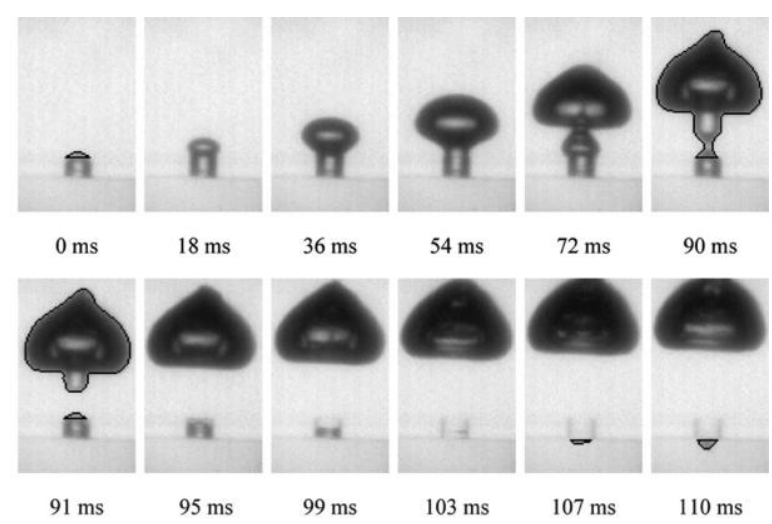

Figure 6: Demonstration of bubble initiation at the tip of orifice $(0 \mathrm{~ms})$, expansion $(0-90 \mathrm{~ms})$ and detachment (91 ms) [26]

The force which mainly tends to hold the expanding bubble to the orifice periphery is the surface tension force [27]. The magnitude of surface tension force is determined by the equation given below:

$F_{\sigma}=\sigma L$

The surface tension force $\left(F_{\sigma}\right)$ acting downward on an expanding bubble is linearly dependent on the contact length $(L)$ between the base of expanding bubble and the orifice periphery [27]. The higher the contact length the higher is the surface tension force and consequently the higher is the bubble expansion time resulting in an increase in bubble size and volume. It is hypothesized that an increase in orifice inclination tends to increase the contact length $(L)$ resulting in a corresponding increase in the surface tension force. Due to the increase in surface tension force the bubble size-volume increases. The bigger bubble detaching from the orifice moves rapidly through the column section 


\section{Chemical Engineering Research Bulletín 17(2015) 18-24}

ultimately resulting in a decrease in overall gas holdup in the column. Therefore the gas holdup in column decreases with increasing orifice inclination in the gas velocities considered.

\section{CONCLUSION}

The effect of orifice inclination in perforated flat plate gas distributor on the overall gas holdup in the column section of a bubble column is studied at various superficial gas velocities. The orifice inclinations considered are $0^{\circ}, 15^{\circ}$ and $30^{\circ}$. Regardless of flow regime, there is no remarkable effect of orifice inclination on the gas holdup at the superficial gas velocities of $2.20-8.50 \mathrm{~cm} / \mathrm{s}$. Nevertheless, an obvious effect is observed at the gas velocities of $0.015-0.076 \mathrm{~cm} / \mathrm{s}$ where a dispersed-bubble regime exists. At the gas velocities of $0.015-0.076 \mathrm{~cm} / \mathrm{s}$, an increase in orifice inclination results in a reduction in the overall gas holdup in the column section. This observation proves the feasibility of changing gas holdup in the column section through the change in orifice inclination in perforated flat plate distributor. Hence it is proposed to take orifice inclination into gas distributor design consideration especially when the columns operate at very low superficial gas velocities such as 0.015 $0.076 \mathrm{~cm} / \mathrm{s}$. Orifice inclination is certainly an alternative option to control the gas holdup. The experimental results can subsequently be applied to the development and validation of proper mathematical model.

\section{Acknowledgement}

The supports from the Department of Chemical Engineering, BUET and BCEF are gratefully acknowledged.

\section{REFERENCES}

[1] Y. T. Shah, B. G. Kelkar, S. P. Godbole. Design parameters estimations for bubble column reactors. AIChE Journal, 1982, 28.

[2] N. Kantarci, F. Borak, K. O. Ulgen. Bubble column reactors. Process Biochemistry, 2005, 40.

[3] M. R. Bhole, J. B. Joshi, D Ramkrishna. CFD simulation of bubble columns incorporating population balance modeling. Chemical Engineering Science, 2008, 63.

[4] A. Kulkarni. Mass Transfer in Bubble Column Reactors: Effect of bubble size distribution. Industrial \& Engineering Chemistry Research, 2007, 46.

[5] R. Lau, W. Peng, L. G. V. Velazquez, G. Q. Yang, L. S. Fan. Gas-liquid mass transfer in high-pressure bubble columns. Industrial \& Engineering Chemistry Research, 2004, 43.

[6] J. L. Xue, M. A. Dahhan, M. P. Dudukovic, R. F. Mudde. Bubble velocity, size, and interfacial area measurements in a bubble column by four-point optical probe. AIChE Journal, 2008, 54.

[7] R. Krishna, J. Ellenberger. Gas holdup in bubble column reactors operating in the churn-turbulent flow regime. AIChE Journal, 1996, 42.

[8] H. M. Letzel, J. C. Schouten, R. Krishna, V. D. Bleek. Gas holdup and mass transfer in bubble column reactors operated at elevated pressure. Chemical Engineering Science, 1999, 54.

[9] S. S. Özturk, A. Schumpe, W. D. Deckwer. Organic liquids in a bubble column: holdups and mass transfer coefficients. AIChE Journal, 1987, 33.

CBangladesh Uni. of Engg. \& Tech.22 


\section{Chemical Engineering Research Bulletín 17(2015) 18-24}

[10] A. Kemoun, B. C. Ong, P. Gupta, M. H. Al-Dahhan. Gas holdup in bubble columns at elevated pressure via computed tomography. International Journal of Multiphase Flow, 2001, 27.

[11] R. Pohorecki, W. Moniuk, A. Zdrojkowski. Hydrodynamics of a bubble column under elevated pressure. Chemical Engineering Science, 1999, 54.

[12] J.J. Heijnen, K. V. Riet. Mass transfer and heat transfer phenomena in low viscosity bubble columns reactors. Chemical Engineering Journal, 1984, 28.

[13] U. Jordan, A. Schumpe. The gas density effect on mass transfer in bubble columns with organic liquids. Chemical Engineering Science, 2001, 56.

[14] M. Bouaifi, G. Hebrard, D. Bastoul, M. Roustan. A comparative study of gas holdup and mass transfer coefficients in stirred gas-liquid reactors and bubble columns. Chemical Engineering and Proceeding, 2001, 40.

[15] J. S. Smith, L. F. Burns, K. T. Valsaraj, L. J. Thibodeaux. Bubble column reactors for waste water treatment. 2. The effect of sparger design on sublation column hydrodynamic in the homogeneous flow regime. Industrial and Engineering Chemistry Research, 1996, 35.

[16] W. D. Deckwer. Bubble column reactor. John Wiley and Sons, Chichester, 1992.

[17] J. J. Heijnen, K. R. Vant. Mass transfer and heat transfer phenomena in low viscosity bubble columns reactors. Chemical Engineering Journal, 1984, 28.
[18] J. C. Charpentier. Mass transfer rates in gas-liquid absorbers and reactors. Advances in Chemical Engineering, II.

[19] F. Magaud, M. Souhar, G. Wild, N. Boisson. Experimental study of bubble column hydrodynamics. Chemical Engineering Science, 2001, 56.

[20] A. Sarrafi, M. Jamialahmadi, $H$. Müller-Steinhagen, J. M. Smith. Gas holdup in homogeneous and heterogeneous gas-liquid bubble column reactors. The Canadian Journal of Chemical Engineering, 1999, 77.

[21] T. J. Lin, K. Tsuchiya, L. S. Fan. On the measurements of regime transition in high-pressure bubble columns. The Canadian Journal of Chemical Engineering, 1999, 77.

[22] R. Krishna, J. Ellenberger, $C$. Maretto. Flow regime transition in bubble columns. International Communications in Heat and Mass Transfer, 1999, 26.

[23] H. M. Letzel, J. C. Schouten, V. D. Bleek, R. Krishna. Influence of elevated pressure on the stability of bubbly flows. Chemical Engineering Science, 1997, 52.

[24] I. G. Reilly, D. S. Scott, T. J. D. Bruijn, D. MacIntyre. The role of gas phase momentum in determining gas holdup and hydrodynamic flow regimes in bubble column operations. Canadian Journal of Chemical Engineering, 1994, 72.

[25] M. C. Ruzicka, J. Zahradnik, J. Drahos, N. H. Thomas. Homogeneous-heterogeneous regime transition in bubble columns. Chemical Engineering Science, 2001, 56.

[26] M. I. Hossain, S. Q. Pang, Q.X. Pang, Y. Yang, R. Lau. Study of 


\section{Chemícal Engineering Research Bulletín 17(2015) 18-24}

liquid weeping at a tapered orifice in a bubble column reactor by a computer-aided image analysis Algorithm. Industrial and Engineering Chemistry Research, 2010, 49.
[27] G. Q. Yang, B. Du, L. S. Fan. Bubble formation and dynamics in gas-liquid-solid fluidization - A review. Chemical Engineering Science, 2007, 62. 